\title{
BMJ Global Health Protecting hard-won gains for mothers and newborns in low-income and middle-income countries in the face of COVID-19: call for a service safety net
}

\author{
Wendy Jane Graham (D) , ${ }^{1}$ Bosede Afolabi, ${ }^{2}$ Lenka Benova, ${ }^{3}$ \\ Oona Maeve Renee Campbell, ${ }^{1}$ Veronique Filippi, ${ }^{4}$ Annettee Nakimuli, ${ }^{5}$ \\ Loveday Penn-Kekana, ${ }^{1}$ Gaurav Sharma, ${ }^{6}$ Uduak Okomo, ${ }^{7}$ Sandra Valongueiro, ${ }^{8}$ \\ Peter Waiswa, ${ }^{9}$ Carine Ronsmans ${ }^{4}$
}

To cite: Graham WJ, Afolabi B, Benova L, et al. Protecting hard-won gains for mothers and newborns in low-income and middle-income countries in the face of COVID-19: call for a service safety net. BMJ Global Health 2020:5:e02754. doi:10.1136/ bmjgh-2020-002754

Received 26 April 2020 Accepted 27 April 2020

\section{Check for updates}

(c) Author(s) (or their employer(s)) 2020. Re-use permitted under CC BY-NC. No commercial re-use. See rights and permissions. Published by BMJ.

For numbered affiliations see end of article.

Correspondence to

Professor Wendy Jane Graham; Wendy.Graham@Ishtm.ac.uk
There are an estimated 5. 4 million largely preventable maternal and perinatal deaths each year. ${ }^{1-3}$ Improving the survival and wellbeing of mothers and newborns is indisputably a global priority. This is as true today as ever and as the world grapples with the COVID-19 pandemic. For maternal and newborn health $(\mathrm{MNH})$, a critical question today is not only the extent to which pregnant or postpartum women and newborns are vulnerable to COVID-19-infection ${ }^{4}$ but also the degree to which the safety of giving birth and accessing treatment for complications in health facilities is being compromised by the direct and indirect effects of the virus, thereby reversing hard progress in $\mathrm{MNH}$ over the last 30 years. We know that infectious disease outbreaks can devastate provision of such care, for example, during the Ebola outbreak in West Africa. ${ }^{5}$ In this commentary, we use insights from those on the ground in low-income and middle-income countries (LMICs) to highlight both the impact of COVID-19 on facility births and the innovative local solutions being adopted to mitigate these effects. We consider how in-country responses to the pandemic might also provide an opportunity to finally tackle key weaknesses in facilities, including low staffing, overcrowding, poor infection prevention and control (IPC), and disrespectful care.

In 2006, the Lancet Maternal Survival Series presented convincing evidence for what is now accepted global strategy: that women should be encouraged and enabled to give birth where labour and childbirth can be managed by a skilled attendant in a safe environment, primarily in health facilities. $^{6}$ The series offered various options for

\section{Summary box}

The adverse impact of COVID-19 on maternal and newborn services in low-income and middle-income countries risks undermining improvements in health outcomes and care achieved over the last three decades.

- Alarming declines in the use of services and in the quality of care in health facilities are being reported from sources on the ground, captured rapidly and in real time using e-communication tools.

- Local solutions to the direct and indirect challenges brought to maternal and newborn health services by COVID-19 must be captured effectively and shared efficiently to support health workers and managers.

- Providing adequate funding to maintain essential services alongside urgent action plans for COVID-19 is essential to enable rapid adaptation and modifications to service delivery in response to different transmission scenarios and stages of the pandemic.

scaling up and mobilising financial resources. The proportion of births in health facilities increased dramatically over the next decade. ${ }^{7}$ In 2016, the second Maternal Health Series celebrated this success but also drew attention to the poor quality of maternity services, from inadequacies in water and sanitation infrastructure to shortages of trained staff, poor IPC, limited access to surgical interventions and essential drugs, and disrespectful and abusive care to women in labour. ${ }^{8}$ What was clear long before COVID-19 is that some facilities are unsafe for the physical and mental well-being of women and newborns and that the most marginalised women often receive the poorest quality of care. ${ }^{9}$

How the pandemic will affect women and newborns is uncertain, as there are many 



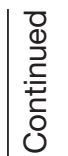
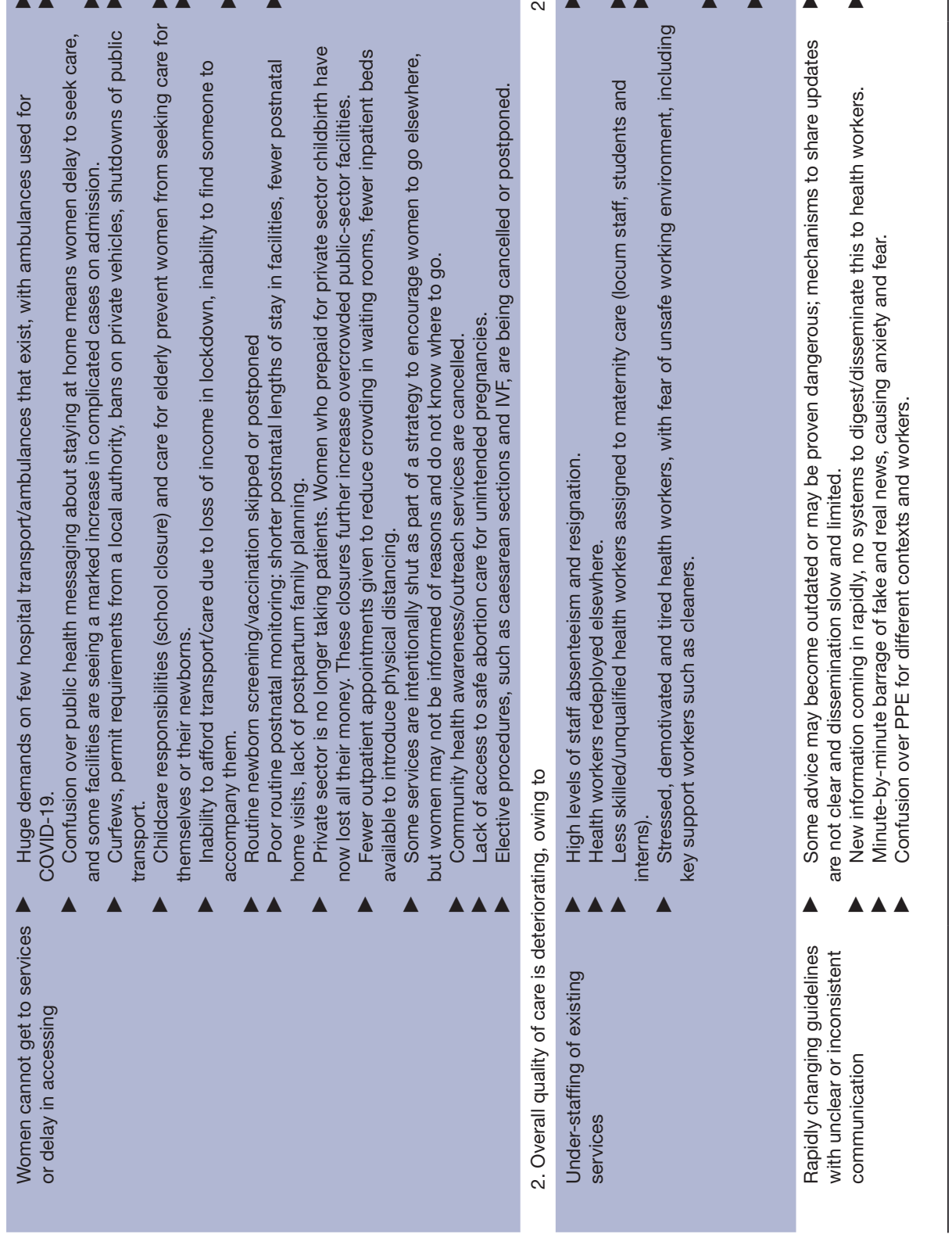


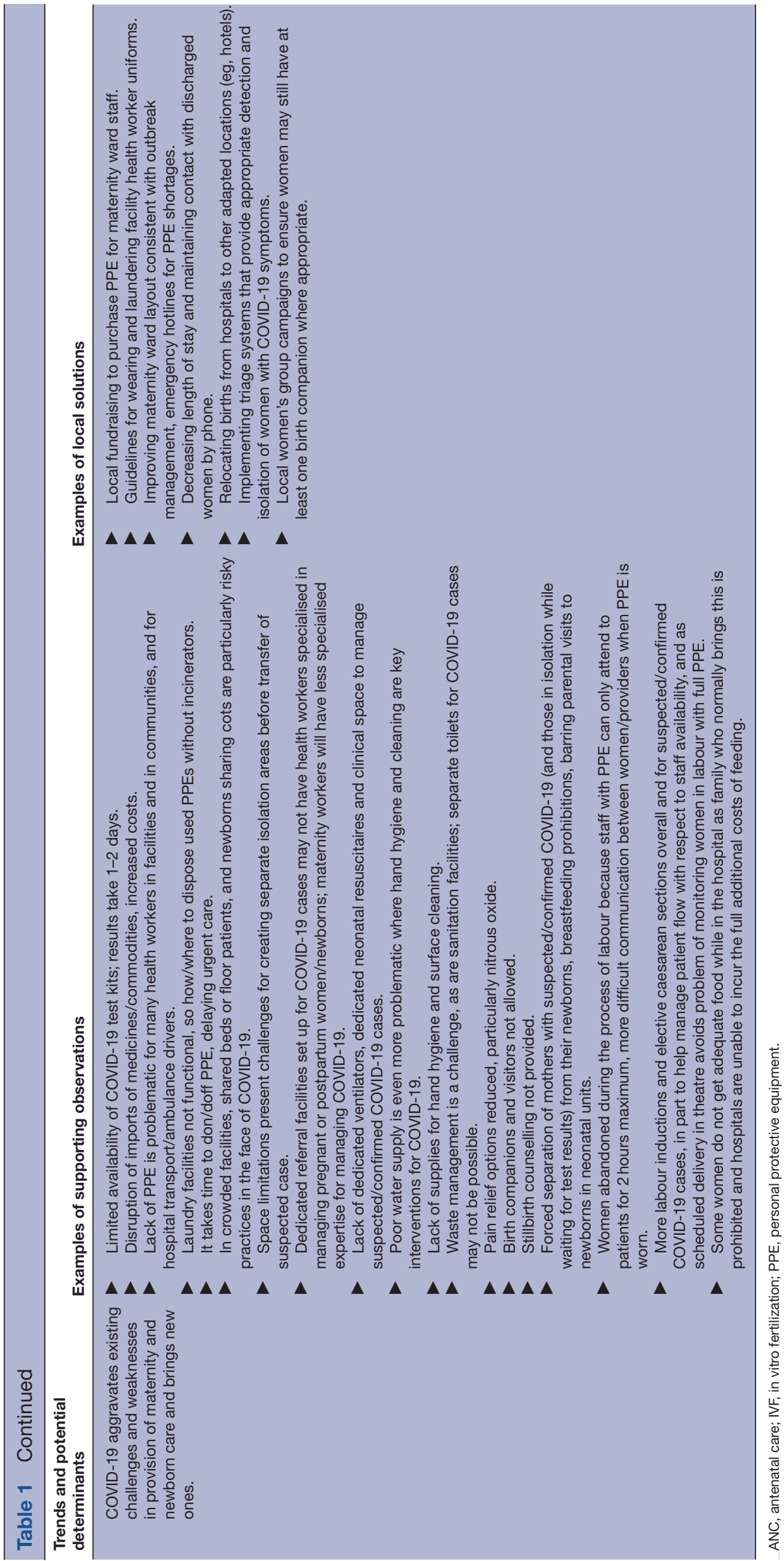

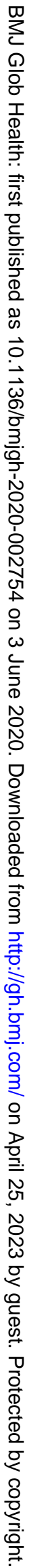


information gaps. For MNH, these fall into three main areas: (1) the epidemiology of COVID-19 infection during and after pregnancy and for the newborn; (2) the clinical management of suspected cases in pregnant or postpartum women and newborns, given the uncertainties in diagnosis and management of COVID-19 in the absence of widespread testing; and (3) the upheaval that the pandemic may be causing in the demand and supply for already-fragile MNH services in LMICs. Here we focus on the third area-the disruption in services-which may well pose the greatest challenge to protecting women and newborns, especially in LMICs. 1011

How do we know whether services are disrupted? The COVID-19 pandemic has halted many routine and periodic data capture systems. Population-based surveys, such as the demographic and health surveys, have been delayed or deferred indefinitely, and routine information sources are not being maintained because of overload on reporting owing to COVID-19 cases, the need to divert resources to infection surveillance, and safety fears for data collectors and interviewees. Where does this leave us? Social media, rapid online surveys and communities of practice are providing a channel for hearing voices on the ground. Some would reject the use of these 'anecdotes', but we argue instead for the capture, synthesis and sharing of this experiential knowledge, with appropriate safeguards for validation and confidentiality.

What do these voices say? Table 1 gives examples of reports received during a recent online survey and webinar organised by the authors. ${ }^{12}{ }^{13}$ Collectively, these voices, hailing from over 60 LMICs, suggest two main trends: declining use of services and deteriorating quality, in some cases dramatically so. The fall in use is being seen across a range of $\mathrm{MNH}$ services, including facility delivery, antenatal care (ANC) attendance, and use of newborn preventive and curative care, and echoes concerns in other areas such as child immunisation (figure 1). These patterns are emerging at early stages of the pandemic, and they may become more marked as transmission accelerates. A recent modelling of the consequences of declining use, of varying degrees and duration, of maternity services estimated an $8.3 \%-38.6 \%$ increase in maternal deaths per month across 118 LMICs. ${ }^{14}$

The catalogue of problems highlighted in table 1 poses a huge dilemma for MNH care. Will deterioration of facility-based care shift the balance of risk to women and newborns from benefit to harm, so challenging the strategic recommendation for facility deliveries? If so, what choices are there for pregnant women and service providers? Should we revisit risk screening approaches and strengthen ANC so that women at lower risk can be advised to give birth in primary care facilities or in separate midwifery units? How can quality be maintained or improved? Once again, responses are emerging from reports on the ground; the final column in table 1 summarises some local solutions to context-specific problems from our online survey and webinar. Collectively, these local adaptations and responses may protect

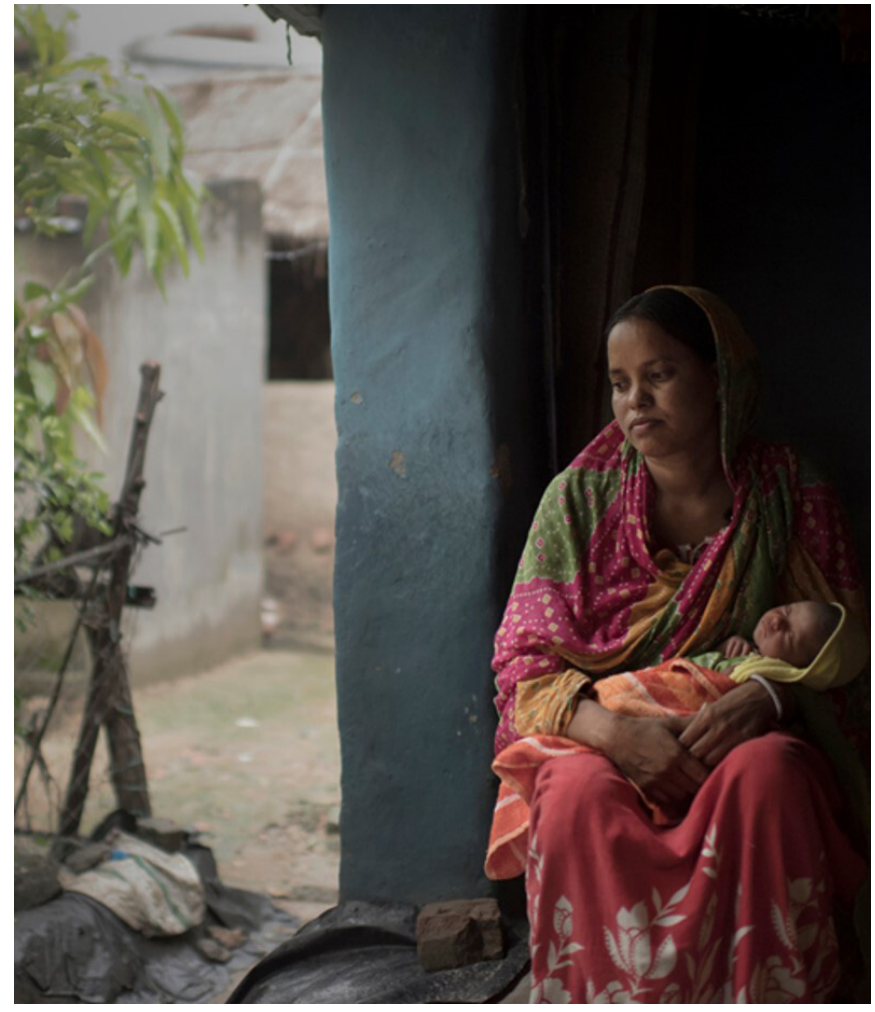

Figure 1 Many women face obstacles to seeking care in health facilities for themselves or their newborn baby (photo credit: Pieter ten Hoopen 2016; license for unrestricted use held by London School of Hygiene \& Tropical Medicine (OMR Campbell and WJ Graham)).

delivery services from further deterioration and so shield women and newborns. Moreover, beyond this immediate protective strategy, it is crucial to optimise on any wider health systems strengthening which may emerge out of the COVID-19 responses in LMICs, ${ }^{15}$ including addressing chronic constraints, such as the shortages and poor working environments of health workers.

The authors call on national governments in LMICs and the international community of agencies and donors grappling with the COVID-19 pandemic to preserve hard-won but fragile gains in $\mathrm{MNH}$ and in services and to protect frontline workers in health facilities who are key drivers of this progress and whose voices we have tried to capture.

We have three main asks of these stakeholders:

1. Maintain routine and essential services for $\mathrm{MNH}$, alongside developing urgent action plans for COVID-19, to prevent further spread of the virus and to care for those infected, and to track policy shifts and innovation and key coverage indicators prospectively.

2. Rapidly establish better ways of both identifying and sharing experiential local knowledge from the frontline on solutions to emerging challenges in MNH service provision and ways of realistically evaluating these adaptations.

3. Provide adequate funding for facilities both to enable rapid adaptations and modifications to service delivery in response to different COVID-19 transmission 
scenarios and stages of the pandemic, and to support sustainable improvements.

These actions are geared towards effectively putting a safety net around MNH services in the face of adversity, so increasing the likelihood of emerging from the COVID-19 pandemic with less adverse impact and more lasting benefits for women and newborns.

\section{Author affiliations}

${ }^{1}$ Infectious Disease Epidemiology, London School of Hygiene and Tropical Medicine, London, UK

${ }^{2}$ Department of Obstetrics and Gynaecology, College of Medicine, University of Lagos, Akoka, Lagos, Nigeria

${ }^{3}$ Department of Public Health, Institute of Tropical Medicine, Antwerpen, Belgium ${ }^{4}$ Infectious Disease Epidemiology, London School of Hygiene \& Tropical Medicine, London, UK

${ }^{5}$ Obstetrics and Gynecology, Makerere University and Mulago National Referral Hospital, Kampala, Uganda

${ }^{6}$ Independent Consultant, Kathmandu, Nepal

${ }^{7}$ Vaccines and Immunity Theme, MRC Unit-Gambia, Banjul, Gambia

${ }^{8}$ Postgraduate Program of Public Health, Universidade Federal de Pernambuco, Recife, Brazil

${ }^{9}$ School of Public Health, Makerere University, Kampala, Uganda

Twitter Wendy Jane Graham @profwendygraham and Lenka Benova @lenkabenova

Contributors WJG initiated the paper and, with CR, OMRC and VF, created the initial outline and wrote the first draft. LB, LP-K, BA, AN, UO, GS, SV and PW provided access to reports from countries. All authors contributed to the revisions to the drafts and approved the final version.

Funding The authors have not declared a specific grant for this research from any funding agency in the public, commercial or not-for-profit sectors.

Competing interests None declared.

Patient consent for publication Not required.

Provenance and peer review Not commissioned; internally peer reviewed.

Data availability statement All data relevant to the study are included in the article or uploaded as supplementary information.

Open access This is an open access article distributed in accordance with the Creative Commons Attribution Non Commercial (CC BY-NC 4.0) license, which permits others to distribute, remix, adapt, build upon this work non-commercially, and license their derivative works on different terms, provided the original work is properly cited, appropriate credit is given, any changes made indicated, and the use is non-commercial. See: http://creativecommons.org/licenses/by-nc/4.0/.

ORCID iD

Wendy Jane Graham http://orcid.org/0000-0003-1473-5342

\section{REFERENCES}

1 World Health Organization, UNICEF, UNFPA, World Bank Group and the United Nations Population Division. Maternal mortality: levels and trends 2000 to 2017. Geneva, Switzerland, 2019.

2 United Nations Inter-Agency Group for Child Mortality Estimation (UN IGME). Levels \& Trends in Child Mortality Estimates developed by the UN Inter-agency Group for Child Mortality Estimation. New York: United Nations Children's Fund, 2018.

3 Blencowe H, Cousens S, Jassir FB, et al. National, regional, and worldwide estimates of stillbirth rates in 2015, with trends from 2000: a systematic analysis. Lancet Glob Health 2016;4:e98-108.

4 Buekens P, Alger J, Bréart G, et al. A call for action for COVID-19 surveillance and research during pregnancy. Lancet Glob Health 2020. doi:10.1016/S2214-109X(20)30206-0

5 Sochas L, Channon AA, Nam S. Counting indirect crisis-related deaths in the context of a low-resilience health system: the case of maternal and neonatal health during the Ebola epidemic in Sierra Leone. Health Policy Plan 2017;32:iii32-9.

7 Campbell OMR, Graham WJ, Lancet Maternal Survival Series steering group. Strategies for reducing maternal mortality: getting on with what works. Lancet 2006;368:1284-99.

8 Campbell OMR, Calvert C, Testa A, et al. The scale, scope, coverage, and capability of childbirth care. Lancet 2016;388:2193-208.

9 Miller S, Abalos E, Chamillard M, et al. Beyond too little, too late and too much, too soon: a pathway towards evidence-based, respectful maternity care worldwide. Lancet 2016;388:2176-92.

10 Gabrysch S, Nesbitt RC, Schoeps A, et al. Does facility birth reduce maternal and perinatal mortality in Brong Ahafo, Ghana? A secondary analysis using data on 119244 pregnancies from two cluster-randomised controlled trials. Lancet Glob Health 2019; 7:e1074-87.

11 Riley T, Sully E, Ahmed Z, et al. Estimates of the potential impact of the COVID-19 pandemic on sexual and reproductive health in low- and middle-income countries. Int Perspect Sex Reprod Health 2020;46:46.

12 UNFPA. COVID-19 technical brief for maternity services, 2020. Available: https://www.unfpa.org/sites/default/files/resource-pdf/ COVID-19_MNH_guidance_04.pdf [Accessed 24 Apr 2020].

13 Semaan A, Audet C, Huysmans E, et al. Voices from the frontline: findings from a thematic analysis of a rapid online global survey of maternal and newborn health professionals facing the COVID-19 pandemic and newborn health, 2020. Available: https://www. medrxiv.org/content/10.1101/2020.05.08.20093393v1.full.pdf [Accessed 12 May 2020].

14 Care-Seeking \& Referral Community of Practice. Recorded webinar on April 21, 2020 "COVID-19 \& MNCH: what's happening on the ground in countries?". Available: https://communities.harpnet.org/ care-seeking-and-referral [Accessed 20 Apr 2020].

15 Roberton T, Carter ED, Chou VB, et al. Early estimates of the indirect effects of the COVID-19 pandemic on maternal and child mortality in low-income and middle-income countries: a modelling study. Lancet Glob Health 2020. doi:10.1016/S2214109X(20)30229-1

16 Kickbusch I, Leung GM, Bhutta ZA, et al. Covid-19: how a virus is turning the world upside down. BMJ 2020;369:m1336. 